\title{
“UM GRANDE EVENTO TÍPICO DO INTERIOR DO BRASIL" NOTAS ETNOGRÁFICAS SOBRE A FESTA DO TOMATE EM PATY DO ALFERES (RJ)
}

Bárbara de Souza Fontes

Este artigo apresenta uma análise etnográfica da Festa do Tomate, que acontece anualmente na cidade de Paty do Alferes (RJ), e consagra a produção agrícola do município, importante produtor de tomate no Brasil. O eixo analítico está centrado no exame de alguns aspectos e eventos em torno dos quais a festa se movimenta: a publicidade, os shows e a política.

ETNOGRAFIA, FESTA DO TOMATE, PATY DO ALFERES, RITUAL.

FONTES, Bárbara de Souza. “Um grande evento típico do interior do Brasil": notas etnográficas sobre a Festa do Tomate em Paty do Alferes (RJ). Textos escolhidos de cultura e arte populares, Rio de Janeiro, v.9, n.2, p. 20-40, nov. 2012. 


\section{"A GREAT EVENT TYPICAL OF THE INTERIOR OF BRAZIL" \\ ETHNOGRAPHIC NOTES ON THE TOMATO FESTIVAL IN PATY DO ALFERES (RJ)}

Bárbara de Souza Fontes

This paper presents an ethnographic analysis of the Tomato Festival, held annually in the city of Paty do Alferes $(R J)$, and enshrines the city's agricultural production as the biggest tomato producer in Brazil. The analytical axis is centered on the examination of some aspects and events around which the party moves: advertising, concerts and politics.

RITUAL, ETHNOGRAPHY, TOMATO FESTIVAL, PATY DO ALFERES.

FONTES, Bárbara de Souza. "Um grande evento típico do interior do Brasil": notas etnográficas sobre a Festa do Tomate em Paty do Alferes (RJ). Textos escolhidos de cultura e arte populares, Rio de Janeiro, v.9, n.2, p. 20-40, nov. 2012. 


\section{INTRODUÇÃO}

A Festa do Tomate é realizada anualmente no município de Paty do Alferes, localizado no interior do estado do Rio de Janeiro, a cerca de $120 \mathrm{~km}$ da capital. A festa acontece há mais de 20 anos, sempre no feriado de Corpus Christi, que ocorre geralmente no mês de junho, ${ }^{1}$ e tem hoje grande projeção no estado. A festa comporta diversas atividades, como grandes shows, concursos - de culinária, de qualidade do tomate, da rainha da festa - e corrida de atletismo, entre outras, que não são do conhecimento da maior parte de seu público, atraído pelo frio e pelos grandes shows.

As festas, enquanto "expressões nítidas e sintéticas da natureza intrinsecamente simbólica do comportamento humano" (CAVALCANTI; GONÇALVES, 2009, p. 8), constituem manifestações inseridas nas teorias de ritual. Sob esse ângulo, a festa pode ser considerada momento extraordinário que condensa aspectos da vida social e individualiza fatos ou relações sociais, colocando-os em foco ao deslocá-los do contexto original, conforme sugere DaMatta (1997).

Cavalcanti e Gonçalves (2010, p. 267) argumentam que as festas, enquanto agregados de comportamento simbólico, realizam, através da "linguagem mediatizada dos símbolos, o trabalho dos ritos". Pensadas como fenômenos totais, no sentido proposto por Mauss (2003), elas seriam mediadoras sensíveis entre passado, presente e futuro, que nos fazem compartilhar e reelaborar experiências anteriores por meio de seu caráter cíclico, e articulam relações que nos projetam também no futuro. Os autores assinalam ainda que as festas constituem fenômenos adequados "à expressão da história, dos valores, dos conflitos e da dinâmica social dos grupos humanos", devido à plasticidade e multiplicidade de seus meios de expressão.

Valeri (1994, p. 410) afirma que "a festa é justamente esse acréscimo da percepção das relações, dado que une na experiência o que está normalmente separado". Nesse sentido, seu personagem central constitui uma representação da totalidade, uma vez que dá unidade a categorias geralmente separadas. Além disso, exige organização, trabalho e orientação às vezes complexa. É mais frequentemente o culminar "da atividade organizada em muitas sociedades, e justifica a perpetuação (...) de formas de agrupamento que têm uma duração permanente e uma influência constante na sociedade" que a produz. Por isso, é tanto uma atividade ritual correlativa da organização social do tempo quanto uma atividade social agradável, o que faz com que seja recordada na memória e tenda a repetir-se no tempo de maneira cíclica. 
Com base nessas formulações este trabalho apresenta a Festa do Tomate, que se refere à produção agrícola do município, que se destaca no cultivo de tomate, e se tornou um ícone identitário de Paty do Alferes. O argumento central deste estudo é pensar esse acontecimento como um processo ritual (TURNER, 1974) articulado no presente, que expressa aspectos da sociedade que a produz. É nessa perspectiva que se desenvolve este artigo, como um desdobramento da etnografia realizada na festa em 2009 e 2010 (FONTES, 2011). Destaca-se que na organização e experiência atual da Festa do Tomate, as categorias de "dentro" e "fora" 2 emergem como oposição analítica central.

\section{A FESTA DO TOMATE}

Desde 1995 a Festa do Tomate dispõe de um lócus permanente para sua realização: o Parque de Exposição Amaury Monteiro Pullig, localizado no distrito de Avelar, a $15 \mathrm{~km}$ do Centro da cidade de Paty do Alferes. Todos os eventos ocorrem nesse cenário festivo, que, com área total ${ }^{3}$ de $4.993,93 \mathrm{~m}^{2}$, é composto por barracas alugadas distribuídas em toda sua extensão, em que são vendidas sobretudo comidas e bebidas. Nas extremidades do Parque há um palco principal e um palco secundário; um parque de diversões; um galpão fixo intitulado "Galpão Vermelho"; uma tenda de artesanatos locais; um "Galpão do Leite"; restaurantes; uma arena de rodeio ${ }^{4}$ e um camarote.

Os eventos festivos condicionam diferentes apropriações do espaço do Parque no decorrer dos dias de festa. Em 2010, durante esse período de suspensão da rotina, foram realizados no Galpão Vermelho o julgamento do Concurso de Qualidade do Tomate e a abertura oficial na manhã de quartafeira; e a premiação da Corrida de Atletismo e do Concurso de Qualidade do Tomate na tarde de domingo. O Concurso da Rainha da Festa, que ocorreu na noite da quarta-feira, e o Concurso de Culinária, na tarde da quinta-feira, foram realizados numa tenda anexa a esse galpão. Os restaurantes abrigaram o almoço dos produtores agrícolas na sexta-feira. No período noturno o espaço do Parque de Exposição foi tomado pelo grande público; pelos grandes shows de artistas conhecidos nacionalmente e pelo rodeio, que aconteceram de quintafeira a domingo. Na noite de quarta-feira e na tarde de domingo os shows foram religiosos. Todos os dias até as 18 horas e na quarta-feira a entrada no Parque de Exposições foi gratuita. O valor do ingresso de domingo foi mais barato em relação aos outros dias: em 2009 e 2010 custou cinco reais enquanto de quinta a sábado custou 15 reais antecipado e 20 reais na hora do evento (estudante paga meia entrada). 
A Festa do Tomate é composta, na verdade, por uma multiplicidade de eventos festivos e heterogêneos. É capaz de agregar, assim, a festa dos jovens, das crianças e dos adultos, bem como dos cristãos protestantes e católicos. Suas atrações musicais vão do rock ao sertanejo, passando pelo pagode, forró e axé, agradando às diversas preferências musicais dos festeiros. Culinária, esporte, agropecuária, política e "beleza" têm seu momento no espaço de lazer que constitui o Parque de Exposição para os frequentadores. Logo, é possível identificar diferentes perspectivas sobre os mesmos fatos, que ajudam a diferenciar os atores sociais e entender que objetivos os motivam a participar dessa festa.

Uma forma de averiguar esse ponto é questionar: o que motiva tantas pessoas migrarem para uma festa longe de sua casa? Uma possível resposta está nos grandes shows, que, entretanto, podem também ser encontrados em outros lugares, até mais próximos das residências do predominante público externo. Segundo Teixeira (1988), o que torna esse tipo de festa tão atrativo é seu cenário. De fato, é no período noturno, do grande público, que emerge o "clima de festa" ou o caráter agradável de que "festa é uma coisa boa". ${ }^{5}$ Desse modo, o que leva os "festeiros a comparecerem em massa às festas são as motivações mais difusas para 'curtir' o 'tempo quente' que elas oferecem". Nesse "tempo quente" ou "clima de festa", a concentração de grande quantidade de pessoas em número reduzido de dias, dentro de espaço delimitado, possibilita alternativas de comportamento mais permissivo, e tudo o que se faz aos poucos na vida cotidiana "na festa se faz de uma vez: rezar, 'festar', comer, competir" (p. 31). Esse fato é claramente percebido na Festa do Tomate, cujos "excessos" são visíveis, principalmente no que se refere ao consumo de bebidas alcoólicas, às brincadeiras entre os grupos de amigos, a "paqueras" e até mesmo brigas.

Magnani (2000, 2002 e 2003) estabelece algumas categorias para analisar as formas de apropriação e usos do espaço. Para o autor (MAGNANI, 2000, p. 32), o "pedaço" caracteriza-se por um espaço demarcado que "tornase ponto de referência para distinguir determinado grupo de frequentadores como pertencentes a uma rede de relações". Nesse sentido, podemos classificar espaços cujos frequentadores não necessariamente se conhecem, mas "se reconhecem enquanto portadores dos mesmos símbolos que remetem (...) a modos de vida semelhantes", como "pedaços". A "mancha", por sua vez, constitui um ponto de referência para um número diversificado de frequentadores que possui base física mais ampla que a do "pedaço" e permite a circulação de pessoas de diferentes origens, sem laços mais estreitos entre si. 
Como esse "tempo quente" emerge no espaço delimitado do Parque de Exposição, tendo a classificar o cenário festivo predominantemente como "mancha", visto que as atividades que oferece e as práticas que propicia (predominantemente no período noturno) "são o resultado de uma multiplicidade de relações entre seus equipamentos, edificações e vias de acesso, transformando-a, assim, em ponto de referência físico, visível e público para um número mais amplo de usuários" (p. 43). Além disso, na mancha há espaço para cruzamentos não previstos, sabe-se o tipo de frequentador que se vai encontrar, mas não quem, e isso é um estímulo para o estabelecimento de redes de sociabilidade e trocas simbólicas.

Durante a festa, moradores de Paracambi, Caxias, Ilha do Governador, Campo Grande, Vassouras, Rio de Janeiro, entre outras localidades, foram questionados sobre os motivos de sua ida. As respostas se referiram à busca de diversão, ao interesse pelas atrações e pela própria festa, a convite de amigos e ao caráter tradicional do evento, entre outras razões. A maior parte dessas pessoas não estava na festa pela primeira vez. Vale destacar um festeiro que comentou ter achado interessante, quando foi pela primeira vez, tratar-se de uma festa do tomate, mas que nada teria visto de extraordinário em relação ao tomate.

A escolha do dia para frequentar a festa é pautada geralmente pelo calendário das atrações, mas os shows propriamente ditos mostram-se secundários quando essas pessoas já estão no Parque. Outras motivações aparecem ainda para esse público "de fora" do município. Assim, moradores de Niterói, Flamengo, Macaé, Copacabana e Barra da Tijuca, ao preencher o questionário aplicado em algumas pousadas, ${ }^{6}$ assim responderam à pergunta "Por que você veio este ano ou frequenta a Festa do Tomate?": "vim com o objetivo de fugir do estresse da cidade grande", "a convite de amigos", "conhecer a festa", "por ouvir boas recomendações", "por indicação de conhecidos dizendo que é uma festa divertida" e para "aproveitar as férias".

Essas motivações integram representações desse público externo, em sua maioria moradores de cidades médias a grandes, que associam a Festa do Tomate aos "de dentro", entendendo por isso uma festa que seria "típica" de cidade pequena. Assim, em relação à pergunta "O que é a Festa do Tomate para você?", houve respostas como: "uma festa típica da cidade de Paty, que movimenta o turismo", "uma festa em uma cidade do interior", "uma festa de exposição e rodeio", "um grande evento típico do interior do Brasil" e, ainda, "uma festa tradicional". Para essas pessoas, é justamente a possibilidade de estar em uma "cidade tranquila", desfrutando de coisas que nem sempre podem 
desfrutar onde moram, como o rodeio, as "comidas", os shows e o próprio frio, o que torna a Festa do Tomate tão atrativa.

Nesse sentido, a sociabilidade festiva seria por si uma das principais motivações para muitas das pessoas que a frequentam. No que se refere ao público externo, essas motivações relacionam-se principalmente a um momento de suspensão da rotina, posto que os shows tornam-se parte de algo maior, que é se relacionar ou se "divertir" junto com os amigos e "aproveitar" o feriado prolongado para descansar.

Essa é também uma importante motivação para os moradores de Paty do Alferes que frequentam a festa, mas não a principal. Para as pessoas "de dentro", sobretudo os jovens, a participação corresponde à satisfação encontrada na suspensão da rotina de uma cidade do interior com poucas possibilidades de lazer. Assim, é a "melhor festa da região", "muito legal por ser apenas uma vez por ano" ou "a única coisa que tem em Paty do Alferes", conforme relataram algumas candidatas ao título de Rainha da Festa. As "pessoas de fora" configuram, aliás, um motivo a mais para ir à festa, que oferece a possibilidade de conhecer pessoas novas e a oportunidade de ver "artistas famosos", ampliando a rede de relações. Como evento anual, a festa gera expectativas e modifica a dinâmica da vida dessas pessoas nesse curto período.

Seja para os moradores, os "de dentro", seja para os visitantes, os "de fora", a circulação noturna tem características especiais que se revelam na própria distribuição espacial dos frequentadores. Assim, há quem vá exclusivamente para o show daquele dia de festa. São os grupos de "fãs", de fato, que logo ao chegar se aglomeram em torno do palco principal. Usam faixas na cabeça e blusas com o nome do artista ou da banda, e almejam ver seus ídolos de perto. Essa é uma parcela pequena do público presente. Há um grupo maior, talvez predominante, que tem também o show como a principal motivação para ir à festa, mas vai sobretudo para se divertir com os amigos. Assistem ao show, mas fazem isso concomitantemente a outras coisas, de forma diferente dos grupos de fãs. Existem ainda aqueles que vão simplesmente para ir, ou seja, pessoas que querem distrair-se, sair da rotina, divertir-se, "zoar". Podem até gostar do show, que, entretanto, não é motivação relevante para estar ali. A escolha do dia de frequência pode estar relacionada ao show no sentido de que há a perspectiva de encontrar pessoas com gostos parecidos ou por ser o dia que "enche mais", mas não é a principal motivação para ir à festa. Muitos permanecem longe do palco, mas perto de alguma barraca, na maioria das vezes bebendo e conversando com os amigos ou em busca de algum flerte. 
Para os atores diretamente envolvidos com a realização do evento, contudo, a motivação de fazer e participar da Festa do Tomate está relacionada à cidade de Paty do Alferes: sua disposição e promoção para assumir as próprias origens. Como chama a atenção a abertura oficial, a festa representa oportunidade de vantagens econômicas e articulações políticas. Nessa perspectiva, a festa surgiria, de acordo com Teixeira (1988, p. 11), "como uma estratégia altamente eficaz para a promoção da cidade-sede do evento, tanto a nível interno como externo". Dado que possuem "um extraordinário poder de mobilização", pode ser vantajoso para pequenas cidades "instrumentalizarem as festas como veículos de sua promoção" (p. 23). Como veremos adiante, a esfera dos discursos corrobora esse fato e permite pensar a festa enquanto celebração da cidade através de um elemento que é visto como constitutivo de seu patrimônio cultural: a produção agrícola de tomate.

Há ainda aqueles para quem a Festa do Tomate é sobretudo sinônimo de trabalho. Nesses casos, mesmo que se trate de um momento de suspensão da rotina, visto que o contexto da festa difere do cotidiano, as motivações para participar estão também atreladas a razões pragmáticas. Assim, seja para os funcionários da prefeitura, que trabalham na festa sem receber hora extra, seja para os "barraqueiros", seja para quem trabalha no parque de diversões, seja para os peões do rodeio, e seja ainda para quem atua nos "bastidores" da festa, como as merendeiras da escola ou os homens que montam a estrutura do Parque, a motivação para realizar uma atividade que aparenta ser puramente racional já vem atrelada ao sistema de significados que envolve trabalhar na Festa do Tomate, e não em outro lugar ou evento qualquer.

Essa amplitude é manifesta também em relação ao sistema de festas da cidade, no qual ocupa lugar central. A Festa do Doce, realizada no Centro da cidade no feriado da Semana Santa, e a Exposição de Orquídeas e Bromélias, realizada no bairro de Arcozelo, durante o feriado da Independência do Brasil, constituem os outros dois eventos com mais apelo depois da Festa do Tomate. Apesar de ambos atraírem pessoas de outros municípios, a maior parte de seu público é local.

A estrutura e o caráter amador da Festa do Doce em relação à do Tomate, por exemplo, chamam a atenção para o tempo de preparo e a quantidade de trabalho que um evento desse porte demanda dos organizadores. Nessa festa, realizada em abril, o prefeito anunciou a contratação para duas atrações da Festa do Tomate de 2010. Na mesma época, as merendeiras responsáveis pela preparação das compotas e doces de tomate vendidos em um estande da Prefeitura Municipal já começavam a prepará-los para a festa. Responsável 
pela realização da festa, a prefeitura, segundo informou o chefe de gabinete do prefeito, "nos seis primeiros meses do ano é só Festa do Tomate". No entanto, é no mês que antecede o evento que essa preparação é intensa e visível. Conforme relatou um funcionário: "A gente costuma falar aqui [na prefeitura] que a Festa do Tomate se autorrealiza; é como se fosse uma entidade. Quando está chegando a época da festa as coisas já começam a se encaminhar, as pessoas já começam a se mobilizar, a nos procurar."

A preparação e o investimento para que a Festa do Tomate seja um "sucesso" envolvem questões que vão muito além do tempo específico de sua realização, que dura apenas cinco dias. Como importante, senão a principal, divulgadora do município e de sua produção agrícola, essa festa funciona como mediadora entre Paty de Alferes e outros municípios e estados. Desse modo, a publicidade e divulgação do município são feitas no sentido de atrair quem é "de fora" para "dentro". Nessa perspectiva, a Festa do Tomate é considerada por muitos moradores "feita para as pessoas de fora" que, como vimos, é o público predominante e que tem perspectiva diferente do público "de dentro". Ao mesmo tempo, a festa é também um importante ícone identitário para os "de dentro", para quem há todo um conjunto de eventos especificamente destinado.

Essa oposição encontrada nas diversas falas entre os de "dentro" e os de "fora" fornece um eixo analítico para o exame de alguns aspectos e eventos da festa que desempenham justamente a função mediadora entre os polos em torno dos quais a festa se movimenta: a publicidade, os shows e a política.

\section{A PUBLICIDADE: DA TERRA DO TOMATE À FESTA DO TOMATE}

Atualmente o município utiliza a publicidade para divulgar sua principal atividade econômica. E, junto com o tomate, sua festa tornou-se ícone identitário do município. Alguns estabelecimentos comerciais têm o tomate em sua propaganda, como é o caso de um posto de gasolina. A prefeitura investe no motivo da festa em sua divulgação, com seu logotipo, bem como das diversas secretarias municipais, trazendo alguma referência visual ao tomate. A Casa do Artesão, localizada em Arcozelo, ${ }^{7}$ vende doces e geleias, bem como lembranças e enfeites com o tema do tomate ou da festa.

Em 2009, ao chegar à cidade de Paty do Alferes para iniciar o trabalho de campo, logo me chamou a atenção uma placa: "Paty do Alferes - A terra da Festa do Tomate". ${ }^{8}$ Como a emancipação do município e o surgimento da festa estão associados, é possível considerar, portanto, a Festa do Tomate um 
elemento constitutivo do patrimônio cultural local. Segundo o primeiro prefeito, a criação da festa está associada à divulgação do então município, já que "a gente precisava de mídia, Paty tinha acabado de se emancipar, a gente precisava tornar a cidade conhecida". De fato, foi comum ouvir dos moradores que "se antes Paty do Alferes era a terra do tomate, hoje é a terra da Festa do Tomate". Para quem é de fora, ${ }^{9}$ a cidade é conhecida majoritariamente como "o lugar onde tem a Festa do Tomate".

Essa situação é semelhante àquela encontrada por Spinelli (2009 , p. 27) em seu estudo sobre as cavalhadas, em Pirenópolis (GO). Nesse caso, a ingerência estatal sobre o município produziu ícones locais destinados a tornar a cidade atrativa ao visitante. Assim, "paralelamente à construção da 'cidade dos Pireneus', desenvolveu-se imagem da 'cidade das cavalhadas', hoje bastante difundida, ao menos a nível regional". A promoção turística da cidade por meio das cavalhadas foi o principal fator para proporcionar "o processo de mudanças na prática cultural que convergiu para a sua atual feição". De modo parecido, o investimento maciço da prefeitura na divulgação do município de Paty do Alferes através da Festa do Tomate parece ter contribuído para deslocar a ideia da "terra do tomate" para a "terra da Festa do Tomate".

Rocha (1985, p. 26), no livro Magia e capitalismo: um estudo antropológico da publicidade, mostrou como "a publicidade retrata, através dos símbolos que manipula, uma série de representações sociais sacralizando momentos do cotidiano". Essas representações possibilitam que o cotidiano se faça vivo e sensível. Por conseguinte, como um "sistema de ideias posto para circular no interior da ordem social", a publicidade é um caminho para compreender relações, comportamentos e expressões ideológicas, constituindo fonte de análise "para o conhecimento de certos sistemas de ideias, representações e do pensamento de uma sociedade" (p. 29). Assim parece ocorrer com a publicidade do tomate através de sua festa ou da festa através de seu tomate, visto que um efeito da publicidade pode ter sido tornar esses dois termos intercambiáveis em Paty do Alferes.

Devido a esse poder de atração e visibilidade que a publicidade da festa proporciona ao município, especialmente no período de sua realização, há todo um investimento em divulgação por parte dos organizadores. Em 2009, como promoção da festa foram colocados $101^{10}$ outdoors em todo o estado, e uma revista ${ }^{11}$ foi vendida nas bancas de jornal do município. A divulgação é feita também através jornais, ${ }^{12}$ da mídia eletrônica, pelo site da festa ${ }^{13}$ e pela televisão local, em propaganda e em uma reportagem feita em 2010 pela TV Rio Sul, ${ }^{14}$ afiliada à Rede Globo. 
Há também preparação específica por parte do comércio e da rede hoteleira para receber quem é de fora, pois "quem sabe ganha dinheiro com a Festa do Tomate", como afirmou uma comerciante. O comércio na cidade, acreditam seus praticantes, durante os dias da festa ganha impulso semelhante ou superior ao da época do Natal. Conforme argumentou a dona de uma pousada, "as próprias pessoas daqui fazem o dinheiro circular mais", comprando roupas para usar na festa ou através de alimentos, como é o caso dos restaurantes, hotéis e pousadas. Essa influência da Festa do Tomate no município é expressa na fala de um morador de Paty do Alferes, envolvido na organização da festa em seus primeiros anos e ainda hoje frequentador:

Quem é que não gosta de ver gente bonita? Gente bem vestida? Porque todo mundo se produz para uma festa dessas. Quem que não gosta de ver? Então é isso que faz o fascínio da festa hoje. Não só, mas ninguém vai para a festa mal vestido, mal produzido, todo mundo quer ir bonitinho. Aí o próprio comércio da cidade, principalmente de roupa, o pessoal compra mais roupa, se embeleza mais, vai arrumar o cabelo (...) É o comércio em geral. É a padaria que vende mais pão, é a farmácia que vende mais remédio, é a feira que vende mais, todo mundo. Porque é uma semana que o dinheiro roda, existe mais gente e existe mais consumo, é normal em toda festa. E é aquele negócio, o ser humano é vaidoso. E isso faz com que a cada dia que passa a festa vá melhorando. E cada governante que entra quer fazer um negócio melhor. Como a Festa do Tomate é o ponto alto da administração dele, então ele vai investir ali (entrevista realizada em 8.6.2009).

Nota-se assim que, aliado à publicidade, está o consumo. ${ }^{15} \mathrm{O}$ investimento publicitário na Festa do Tomate influencia o consumo em Paty do Alferes seja de forma direta, através dos produtos vendidos na festa ou do consumo de roupas, ou indireta, através do comércio no município. Douglas e Isherwood (2009), no livro $O$ mundo dos bens: para uma antropologia do consumo, mostram como o consumo constitui fenômeno de ordem cultural e social, que regula relações sociais e estrutura valores. Cavalcanti (2004, p. 3 e 4), em resenha a esse livro, chama a atenção para o fato de que "consumir é estabelecer vínculos pessoais e sociais através das coisas". Por conseguinte, é um ato ritual, exercido de forma pública e convencional ao corresponder a "definições coletivas da realidade e a um padrão geral de bens e serviços disponíveis". Nessa perspectiva, o consumo tem funções comunicativas, ou seja, pode "transmitir informações acerca do estilo de vida para os outros membros 
da sociedade e refletir, para os próprios consumidores, a evidência da ordem do mundo que eles criaram e habitam".

Assim, por mais que a temperatura na época da festa seja baixa, com média de $10^{\circ} \mathrm{C}$, existe um simbolismo em torno do frio, que faz a Festa do Tomate também ser por isso conhecida pelo público externo. Desse modo, se em Paty os visitantes compram "tantos" casacos, mesmo que venham de lugares onde não faz "tanto frio", como relatou uma comerciária, ou se as mulheres compram botas e casacos de couro, vestindo-se em função da Festa do Tomate, o fazem como resposta a determinado padrão de consumo relacionado às representações sobre a festa e ao estilo de vida dessa localidade.

O mesmo ocorre durante a Festa do Tomate. A tenda do artesanato local montada no Parque tem artigos de diversos tipos referentes à festa, e as barracas que vendem comidas e bebidas "típicas" são concorridas, com seus licores, doces e compotas à base de tomate. Como relatou uma doceira, "nesta época a procura cresce muito. Quem é de fora quer provar um brigadeiro, uma geleia de tomate. As pessoas querem levar uma lembrança da Festa do Tomate". Com isso, a função mediadora da publicidade e do consumo transmite-se para além de Paty do Alferes, pois quem é de fora leva "lembranças" da festa e importantes informações acerca do município: a produção agrícola e a festa em sua homenagem.

\section{"ATRAÇÕES PARA TODOS OS GOSTOS"16": OS SHOWS}

Concentrados em um palco de $250 \mathrm{~m}^{2}$ localizado em uma das extremidades do Parque de Exposição, os grandes shows mobilizam, de alguma forma, toda a extensão do cenário festivo. ${ }^{17}$ Como grande publicidade, já que são considerados por muitos frequentadores as principais atrações, os efeitos dos shows extrapolam em muito seu local de realização no Parque de Exposição. Funcionam como importantes marcadores da passagem do tempo e como mediadores para fora, atraindo o público externo ao município.

Os grandes shows tiveram papel relevante na reconfiguração da Festa do Tomate. Segundo muitos relatos de moradores, o evento outrora "aconchegante", "mais família" transformou-se ao longo dos anos em uma festa voltada para o público externo. Esse grande público que acorre à cidade permite que a economia do município se movimente principalmente através do comércio e da rede hoteleira. Para os patyenses, entretanto, isso teria acarretado a perda de vista daqueles a quem a festa inicialmente se destinava: os produtores agrícolas do município. Nesse sentido, cabe à prefeitura, 
enquanto responsável pela organização do evento, mediar a tensão que surge entre os "de dentro" e os de "fora":

O que a gente encontrou foi uma festa que ficou muito tradicional como evento, como show, e, perdendo um pouco a característica do produtor, ela afastou um pouco do produtor, diferente da proposta inicial. Então a gente vem tentando conciliar a festa como um grande evento porque isso é bom para a cidade, é bom para o comércio, é bom para as pousadas, é bom para os hotéis, é bom para a cidade no geral; mas também não perder a característica de um concurso técnico. Então a gente vem tentando conciliar esses dois lados, ou seja, incentivar técnicas, trazer o produtor de volta para a festa (...) enfim, a ideia é incentivar novas técnicas através do concurso [de qualidade do tomate] e também criar alguma coisa em termos de gastronomia de tomate, é uma ideia que a gente tem. É um evento muito grande, tem uma responsabilidade muito grande porque ele chegou a um nível que a gente tem pelo menos que mantê-lo. De grandes shows, shows de grande porte. A grande dificuldade é você manter o padrão da festa. A cada ano as pessoas cobram mais, todo mundo quer que traga bandas novas, cantores novos, então é uma dificuldade (prefeito Rachid Elmôr, entrevista realizada em 22.10.2010).

É interessante notar que, ao mesmo tempo em que os grandes shows seriam indiretamente responsáveis por uma crítica, eles também são aguardados, celebrados e vistos como motivo de orgulho. Orgulho da cidade pequena que é capaz de trazer os grandes, senão os maiores, artistas do Brasil para tocar em sua terra. Em conversas com moradores, era muito comum ouvilos listarem os grandes artistas que já tinham tocado na festa. "Esses artistas todos já vieram aqui. Todo mundo famoso que está na mídia que você imaginar já veio aqui", declarou uma senhora de Avelar.

Nessa perspectiva, é possível notar uma avaliação da festa de acordo com os shows, que emergem como marcadores da passagem do tempo. Foi comum, quando conversávamos sobre a festa, os moradores se referirem ao evento listando shows de que gostaram, de que não gostaram ou que gostariam ainda de ver. Assim, os anos das festas, bem como sua avaliação como boa ou ruim, são associados ao ou marcados pelo show $\mathrm{X}$ e/ou Y e/ou Z, ${ }^{18}$ como exemplificou um guarda municipal: "o que marcou nessa festa foi o trânsito do show da Ivete e o frio do show de Sandy e Júnior". 


\section{OS "HOMENS COM PODER"}

A abertura oficial, que traz a forte presença dos políticos, é um importante mediador para fora ao inserir o município num circuito político mais amplo. Kuschnir (2007) chama a atenção para a relação entre a política e os rituais, posto que estes reforçam e atualizam papéis sociais. De forma semelhante às festas, os papéis sociais na política têm caráter cíclico que precisa ser reforçado. As festas, enquanto lócus de sociabilidade por excelência, "tornam-se lugares privilegiados para se fazer política" (p. 40), especialmente em época de eleição. Como pontua a autora, eventos como as festas são formas lúdicas de os políticos, como seus promotores, fazerem ofertas aos eleitores, combinando "doação/hierarquia e congregação/igualdade" (p. 41).

Frente à natureza mais informal dos eventos da Festa do Tomate, a abertura oficial adquire caráter formal e solene. Realizada na quarta-feira, seu horário depende da agenda do governador do estado do Rio de Janeiro. De acordo com o ex-prefeito do município, Eurico Júnior, a abertura da festa conta com a presença do governador desde a década de 1990, quando o então governador Marcelo Alencar compareceu. Em 2009 e 2010, foi realizada pela manhã, com o atual governador, Sérgio Cabral, chegando ao Parque de Exposição de helicóptero.

Compareceram à abertura de 2010 vereadores, secretários, prefeitos e delegados, de municípios como Paraíba do Sul, Três Rios, Engenheiro Paulo de Frontim, Paracambi, Vassouras, Miguel Pereira e Mendes, entre outros; bem como deputados estaduais e o vice-governador acompanhado da comitiva do governador. Assistiram também à cerimônia de abertura funcionários da prefeitura e pessoas do município, como estudantes uniformizados e famílias com crianças, principalmente de Avelar, por se tratar ainda de dia útil.

Teixeira (1988) assinala que esse tipo de festa pode ser considerado representação teatral, no sentido de que tem um palco (o Parque de Exposição), autores (a Prefeitura Municipal em parceria com empresas privadas) e atores (homens com poder e mulheres com beleza - representadas pelo Concurso Rainha da Festa do Tomate). Esses "homens com poder"19 são em sua maioria políticos, que recebem homenagens e distinções, e deles se espera que façam doações, além de sua presença atribuir prestígio ao evento. Na festa existe ainda a oportunidade de esses homens ficarem ao alcance mais direto das comunidades locais e regionais, e de ocorrer a liberação de recursos públicos e abertura de linhas especiais de créditos. De fato, foi o que ocorreu em 2009, quando o governador prometeu a construção da estrada que liga Paty do Alferes 
a Petrópolis e a liberação de linhas de créditos para os produtores rurais, através do Programa Nacional de Apoio à Agricultura Familiar - Pronaf, do Banco do Brasil. Nesse ponto é possível perceber como a Festa do Tomate, enquanto fator agregador, é capaz de articular relações que extrapolam o momento imediato do evento festivo. É nesse sentido que o primeiro prefeito do município falou sobre a presença do governador na festa:

Se você for olhar, nenhum município teve tanta obra que beneficiou tanto a população quanto a gente. E muito pela festa, pela presença do governador na Festa do Tomate, na abertura. Porque não tem jeito, é do homem, é da vaidade ver aquele público enorme. Você quer fazer uma graça, e a graça que ele fez foi prometer uma obra (...) Foram várias obras que aconteceram por causa da presença do governador na Festa do Tomate. Era mais fácil. Você é prefeito e vai lá "governador estou precisando disso", "ah, não tenho dinheiro não". Falar com o prefeito em uma sala que ninguém escuta é fácil. Eu quero ver falar na frente de mil pessoas que não vai fazer nada (Eurico Júnior em entrevista realizada em 20.5.2010).

Entre os atores da festa, o prefeito do município se destaca também enquanto anfitrião. Segundo Teixeira (1988, p. 46), ele representa, assim, papéis duplamente importantes, pois acolhe os demais convidados e expõe a necessidade das comunidades locais, solicitando auxílios. Em seu discurso da cerimônia de abertura, algumas questões são recorrentes: "o progresso da região/cidade, seus problemas e soluções e exaltação da operosidade da população local, com grande ênfase no trabalho dos colonos". No caso do atual prefeito de Paty do Alferes, Rachid Elmôr, essa ênfase foi ainda maior porque ele próprio é produtor rural. Em seu discurso na abertura de 2009, mencionou a preocupação do governador com o interior, considerando a festa uma "conquista dos produtores", dedicando-a "aos amigos produtores". Além disso, afirmou ser a festa um "evento político que leva o nome aos estados e municípios", e expressava o desejo de que ela se tornasse também um evento de negócios.

O prestígio da cerimônia de abertura torna-a propícia às homenagens a personagens relacionados à festa ou a sua temática. Em 2009, o primeiro prefeito do município, Eurico Júnior, foi homenageado pela Câmara Municipal com uma placa de agradecimento ${ }^{20}$ pela criação da Festa do Tomate em 1989. Em 2010, a homenagem foi feita aos japoneses, responsáveis pela introdução da tecnologia e cultivo do tomate na região. Representando os japoneses, Hiroshi Watanabe recebeu placa de "Homenagem de Honra ao Mérito à Comunidade Japonesa de Paty do Alferes", entregue pelo governador Sérgio Cabral em 
um pequeno restaurante de comida japonesa montado para a cerimônia de abertura dentro do estande do Japão.

Conforme argumenta Teixeira (1988, p. 43), as doações e o prestígio desses atores políticos são elaborados "no marco do 'sistema de prestações totais'", no sentido proposto por Mauss (2003), uma vez que "em troca" preservam ou aumentam seus poderes. Além do plano individual, tratase de trocas entre "comunidades locais/regionais e sociedade abrangente, representadas na festa por agentes especiais com poder para doar em nome dela" (p. 44). Em retribuição esses 'agentes especiais' são cercados de atenções e recebem brindes da produção local. As homenagens aos atores locais constituem também uma forma de reciprocidade, já que esses 'personagens' que muito já fizeram, agora são agraciados e recebem em troca o reconhecimento. Por outro lado, alguns dos 'homens com poder' procuram a festa pelo que eles mesmos poderão receber. São os políticos da cidade/ região, que "aproveitam a oportunidade para aprofundar esforços no sentido de se legitimarem como seus representantes e assim tentarem novos sucessos eleitorais" (p. 45). Os discursos do governador Sérgio Cabral e do prefeito Rachid Elmôr na abertura da festa de 2010, foram sugestivos.

O governador iniciou seu discurso legitimando a presença dos políticos ao citar todos pelo nome, que, em troca, receberam o reconhecimento público por estar prestigiando o evento. Na abertura de 2010 estavam expostos no Parque os ônibus escolares e as máquinas agrícolas citadas nos discursos que, assim como a promessa da construção de mais uma estrada para o município, de juros zero para o Pronaf e o "cumprimento" do compromisso pela estrada Paty-Petrópolis, estabelecido na festa de 2009, fazem parte desse sistema de prestações totais. A cesta composta por doces e compotas feitas com o tomate para presentear a equipe do governador surgiu como forma de retribuição dentro desse sistema. Por conseguinte, o caráter repetitivo da festa permite que o sistema de trocas se renove e se mantenha porque, conforme argumenta Mauss (2003, p. 236 e 237), "a dádiva implica necessariamente a noção de crédito" visto que "o tempo é necessário para executar qualquer contraprestação".

\section{CONSIDERAÇÕES FINAIS}

A realização da Festa do Tomate mobiliza anualmente Paty do Alferes de diversas formas. Nos dias de hoje, a festa é um importante ícone identitário desse município, mas podemos dizer que a história de ambos se entrelaça e se constrói a partir da produção agrícola de tomate da região. Se a característica 
do município de importante produtor de tomate foi-se retraindo ao longo dos anos, a Festa do Tomate, ao contrário, ganhou vulto e extrapolou as fronteiras da localidade. Transferiu, de certa forma, o título de "terra do tomate" atribuído pelos moradores à Paty do Alferes, para "terra da Festa do Tomate", como a própria publicidade do município evidencia.

De forma semelhante ao caso de Parintins, o objeto da pesquisa realizada é a festa entendida como um fato total (Mauss, 2003), visto que se expressa atualmente, como observa Cavalcanti (2000, p.1020), "com sua intensa capacidade de integração cultural e com os problemas e contradições inerentes à sua expansão". Basta adentrar o cenário festivo e acompanhá-la em seus cinco dias para perceber que a Festa do Tomate é "muito mais que uma festa", ${ }^{21}$ posto que envolve diretamente as dimensões político-econômicas da cidade, bem como agrega o nível religioso (expresso pelos shows católicos e gospel, e pelo rodeio) e o secular da vida social.

Entendida como a culminância de um processo ritual (TURNER, 1974), a Festa do Tomate ressoa a experiência dos atores que dela participam, já que, conforme assinala Gonçalves (2007, p. 215), citando Greenblatt, essa ideia de ressonância associa-se ao poder do objeto de evocar no espectador as forças culturais das quais ele emergiu e das quais ele é o representante, para além de suas fronteiras formais. Logo, para os festeiros "de fora", ela evoca a produção agrícola de tomate no município e, para aqueles "de dentro", organiza uma experiência social diluída no cotidiano.

Além disso, enquanto processo ritual compreendido no fluxo da vida 'real', podemos pensar a Festa do Tomate como o momento de um consenso mínimo de unidade para Paty do Alferes. Ao domesticar uma temporalidade externa, da metrópole, a festa se torna o lugar do ecletismo numa cidade pequena. Assim, incorporando na experiência dessa localidade o mundo cosmopolita, a Festa do Tomate cumpre um papel reflexivo sobre a própria existência desse município.

\section{REFERÊNCIAS BIBLIOGRÁFICAS}

CAVALCANTI, Maria Laura Viveiros de Castro. O boi-bumbá de Parintins, Amazonas: breve história e etnografia da festa. História, Ciências, Saúde - Manguinhos, vol.6 (suplemento), p.1019-1046. Rio de Janeiro: Fiocruz, 2000.

. Mary Douglas: dama da ordem e das fronteiras. O Globo, Caderno Prosa e Verso, 25/12/2004, Rio de Janeiro.

; GONÇALVES, José Reginaldo Santos (orgs.) As festas e os dias: ritos e sociabilidades festivas. Rio de Janeiro: Contra Capa, 2009. 
. Cultura, festa e patrimônio. In: DUARTE, Luiz Fernando Dias (Org.). Horizontes das ciências sociais no Brasil - Antropologia. 1. ed. São Paulo: Anpocs/Ed. Barcarolla/ Discurso Editorial, v. 1, p. 259-292, 2010.

DAMATTA, Roberto. Carnavais, malandros e heróis: para uma sociologia do dilema brasileiro. Rio de Janeiro: Rocco, 1997.

DOUGLAS, Mary; ISHERWOOD, Baron. O mundo dos bens: para uma antropologia do consumo. Rio de Janeiro: Editora UFRJ, 2009.

FONTES, Bárbara de Souza. Entre o labor e o sabor: A Festa do Tomate em Paty do Alferes (RJ). Dissertação (mestrado) - Programa de Pós-Graduação em Sociologia e Antropologia. Universidade Federal do Rio de Janeiro. Rio de Janeiro, 2011.

GONÇALVES, José Reginaldo. Antropologia dos objetos: coleções, museus e patrimônios. Rio de Janeiro: Departamento de Museus e Centros Culturais/ Iphan, 2007.

KUSCHNIR, Karina. Antropologia da política. Rio de Janeiro: Jorge Zahar, 2007.

MAGNANI, José Guilherme Cantor. Quando o campo é a cidade: fazendo antropologia na metrópole. In: MAGNANI, José Guilherme Cantor e TORRES, Lílian (orgs.). Na metrópole: textos de antropologia urbana. p. 12-53. São Paulo: Edusp, 2000.

. De perto e de dentro: notas para uma etnografia urbana. Revista Brasileira de Ciências Sociais, São Paulo, v. 17, n. 49, 2002.

. Festa no pedaço: cultura popular e lazer na cidade. São Paulo: Editora Unesp, 2003.

MAUSS, Marcel. Sociologia e antropologia. São Paulo: Cosac Naify, 2003.

ROCHA, Everardo. Magia e capitalismo: um estudo antropológico da publicidade. São Paulo: Brasiliense, 1985.

. A sociedade do sonho: comunicação, cultura e consumo. Rio de Janeiro: Mauad, 1995.

SPINELLI, Celine. Cavaleiros de Pirenópolis: etnografia de um rito equestre. Dissertação (mestrado) - Programa de Pós-Graduação em Sociologia e Antropologia, Universidade Federal do Rio de Janeiro, Rio de Janeiro, 2009.

TEIXEIRA, Sérgio Alves. Os recados das festas: representações e poder no Brasil. Rio de Janeiro: Instituto Nacional de Folclore/Funarte, 1988.

TURNER, Victor. O processo ritual: estrutura e antiestrutura. Petrópolis: Editora Vozes, 1974.

VALERI, Valério. Verbete “Festa”. Enciclopédia Einaudi, p. 406-412. Lisboa: Imprensa Nacional, 1994.

\section{NOTAS}

1 Trata-se de feriado sem data fixa que ocorre 60 dias depois da Páscoa, geralmente em maio ou junho. O feriado acontece invariavelmente em uma quinta-feira 
e "emenda" com o final da semana, mas a festa começa na quarta-feira com a abertura oficial do evento.

2 A expressão "de fora" é categoria nativa utilizada pelos moradores para se referir ao público externo; "de dentro", por sua vez, é expressão utilizado para compor essa oposição analítica.

3 Fonte: Secretaria de Planejamento de Paty do Alferes. Esses números se referem à planta da festa de 2010.

4 A arena de rodeio voltou a fazer parte da festa em 2009, depois de nove anos de ausência.

5 Durante o trabalho de campo foram distribuídos questionários em cinco pousadas de Paty do Alferes, focalizando as percepções do público externo, e entre as concorrentes do Concurso da Rainha da Festa, sendo uma das perguntas: "O que é uma festa boa para você?" É interessante notar variações nas respostas entre os "de dentro" e os "de fora" do município. Assim, enquanto seis das 12 concorrentes responderam que uma festa boa é "a Festa do Tomate", os 15 "de fora" deram respostas mais amplas no questionário, relacionadas à organização, segurança, infraestrutura, "boa música", "boa comida" e "diversão". Algumas respostas apontaram fatores subjetivos, como "ter um clima agradável", "calor humano" ou ainda "uma festa boa somos nós que fazemos".

6 Foram entregues 50 questionários em cinco pousadas, e 15 pessoas responderam.

7 Bairro de Paty do Alferes.

8 Essa placa existe no pórtico de entrada do município, no Centro da cidade e na entrada do distrito de Avelar, que abriga a festa. Arcozelo, bairro em que a festa começou, exibe a placa "Festa do Tomate".

9 No processo de desenvolvimento da pesquisa é interessante que, sempre que eu comentava sobre a Festa do Tomate ou Paty do Alferes, imediatamente as pessoas conheciam, ou já tinham "ouvido falar" na festa e, por seu intermédio, identificavam o município.

10 Segundo uma funcionária da empresa contratada pela prefeitura para organizar a festa naquele ano.

11 Com o título Tomate é Festa, essa revista traz a programação da Festa do Tomate, com ênfase nas atrações musicais, entrevistas com o prefeito e o secretário de Agricultura; opções de passeio, hospedagem e a história de Paty do Alferes, além de matérias sobre o tomate, com os temas de saúde, gastronomia e meio ambiente.

12 A maior parte da divulgação é feita através de jornais da região, mas jornais de maior circulação, como $O$ Globo e $O$ Dia também publicaram matérias sobre a festa.

13 http://www.patyfestadotomate.com.br/ e http://www.festadotomate2010. com.br/, com transmissão ao vivo da festa. 
14 A reportagem foi exibida no RJTV. Está disponível em: http://riosulnet.globo. com/web/conteudo/1_269325.asp

15 Ver a respeito Rocha, 1995.

16 Título de um capítulo do livro de Teixeira (1988).

17 Há também no Parque de Exposição o "Palco 2", destinado a shows de artistas regionais, que ocorrem antes da apresentação principal e têm público reduzido. Em 2009 o "Palco 2" ficou localizado na extremidade oposta ao principal, e em 2010 eles foram montados lado a lado.

18 Cada festa costuma ter, no mínimo, quatro grandes atrações musicais, visto que as apresentações são de quinta-feira a domingo. A quarta-feira é destinada ao público gospel. Em 2009 e 2010 seis artistas de renome nacional se apresentaram, em cada ano, na Festa do Tomate.

19 É importante ressaltar que utilizo a expressão do autor por se tratar de um momento da festa em que os atores são predominantemente homens, apesar de reconhecer a existência de mulheres atuantes nessa esfera, como a ex-prefeita de Paty do Alferes, que governou durante oito anos.

20 "No 1ㅇano de Administração da Prefeitura Municipal e por ter aprovado a Logomarca Oficial do Evento que este ano completa 21 anos, criado pelo então Presidente da TurisRio Sérgio Cabral Filho, hoje Governador do Estado do Rio de Janeiro."

21 Essa frase foi coletada do cartaz de divulgação da festa de 2009.

Bárbara de Souza Fontes é mestre em sociologia e antropologia pelo PPGSA/ IFCS/UFRJ, bacharel e licenciada em ciências sociais pela UFRJ. 